
When U. S. Government drawings, specifications, or other data are used for any purpose other than a definitely related Government procurement operation, the Government thereby incurs no responsibility nor any obligation whatsoever, and the fact that the Government may have formulated, furnished, or in any way supplied the said drawings, specifications, or other data, is not to be regarded by implication or otherwise, or in any manner licensing the holder or any other person or corporation, or conveying any rights or permission to manufacture, use, or sell any patented invention that may in any way be related thereto.

References to named commercial products in this report aro not to be considered in any serise as an endorsement of the product by the United States Air Force or the Government. 
ANL/EP/AS-89/3
Argonne National Laboratory
9700 South Cass Avenue Argonne, Illinois 60439

\title{
NUCLEATION OF COPPER DURING SUPERSONIC EXPANSION
}

\author{
by
}

\author{
R. K. Ahruwalia and K. H. Im
}

Engineering Physics Division

\section{DISCLAIMER}

\begin{abstract}
This report was prepared as an account of work sponsored by an agency of the United States Government. Neither the United States Gnvernment not any agency thereof, nor any of their employees, makes any warranty, express or implied, or assumes any legal liability or responsibility for the accuracy, completeness, or usefulness of any information, apparatus, product, or process disclosed, or represents that its use would not infringe privately owned rights. Reference herein to any specific commercial product, process, or service by trade name, trademark, manufacturer, or otherwise does not necessarily constitute or imply its endorsement, recommendation, or favoring by the United States Government or any agency thereof. The views and opinions of authors expressed herein do not necessarily state or reflect those of the United States Government or any agency thereof.
\end{abstract}

December 1989 
SUMMARY.

1.0 INTRODUCTION......................................... 5

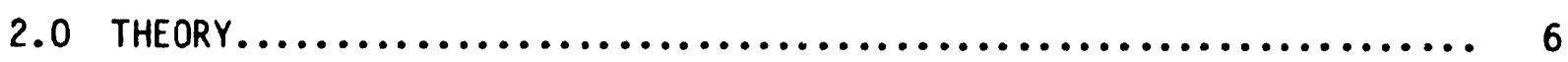

2.1 Non-Steady State Nucleation Theory..................... 8

2.2 Stable Cluster Population............................ 10

2.3 Monomer Concentration............................ 11

3.0 RESULTS AND DISCUSSION............................ 11

3.1 Cluster Dynamics................................. 12

3.2 Sensitivity to Surface Energy....................... 12

3.3 Sensitivity to Monomer Concentration................... 16

3.4 Sensitivity to Exit Temperature...................... 18

3.5 Sensitivity to Exit Pressure....................... 18

3.6 Sensitivity to Exit Mach Number...................... 20

3.7 Copper Oxide Condensation........................... 20

4.0 CONCLUSIONS AND RECOMMENDATIONS ....................... 22 


\section{LIST OF ILLUSTRATIONS}

Figure

Page

1. Time Scales for Nucleation Delay and Supersaturation Doubling...... 7

2. Critical Cooling Rate............................... 7

3. Cluster Dynamics...................................... 13

4. Sensitivity of Stable Cluster Size Spectrum to Surface Energy $\left(T_{e}=1000 \mathrm{~K}, P_{e}=0.5 \mathrm{~atm}, M_{e}=3.5, x_{i}=100 \mathrm{ppm}\right) \ldots \ldots \ldots \ldots \ldots \ldots 15$

5. Variation of Supersaturation Ratio and Nucleation Rate During the Expansion Process $\left(T_{e}=1000 \mathrm{~K}, P_{e}=0.5 \mathrm{~atm}, M_{e}=3.5\right.$. $\left.x_{i}=100 \mathrm{ppm}, \sigma=0.8 \mathrm{~N} / \mathrm{m}\right)$.

6. Effect of Monomer Concentration on Formation of Stable Clusters $\left(T_{e}=1000 \mathrm{~K}, P_{e}=0.5 \mathrm{~atm}, M_{e}=3.5, \sigma=0.8 \mathrm{~N} / \mathrm{m}\right) \ldots \ldots \ldots \ldots \ldots \ldots 17$

7. Effect of Nozzle Exit Temperature on Formation of Stable Clusters $\left(P_{e}=0.5 \mathrm{~atm}, M_{e}=3.5, x_{i}=100 \mathrm{ppm}, \sigma=0.8 \mathrm{~N} / \mathrm{m}\right) \ldots \ldots \ldots \ldots \ldots \ldots 19$

8. Effect of Nozzle Exit Pressure on Formation of Stable Clusters $\left(T_{e}=1000 \mathrm{~K}, M_{e}=3.5, x_{j}=100 \mathrm{ppm}, \sigma=0.8 \mathrm{~N} / \mathrm{m}\right) \ldots \ldots \ldots \ldots \ldots \ldots 19$

9. Effect of Nozzle Exit Mach Number on Formation of Stable Clusters $\left(T_{e}=1000 \mathrm{~K}, P_{e}=0.5 \mathrm{~atm}, x_{i}=100 \mathrm{ppm}, \sigma=0.8 \mathrm{~N} / \mathrm{m} . \ldots \ldots \ldots \ldots . .21\right.$

10. Cu0 Condensation ( $T_{e}=1000 \mathrm{~K}, \mathrm{P}_{\mathrm{e}}=0.5 \mathrm{~atm}, \mathrm{M}_{e}=3.5$,

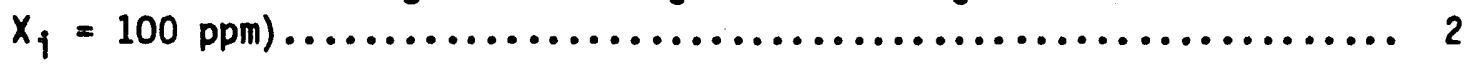




\section{LIST OF TABLES}

Table

Page

1. Reference Data..................................... 12

2. Sensitivity to Monomer Concentration....................... 16

3. Sensitivity to Nozzle Exit Temperature..................... 18

4. Sensitivity to Nozzle Exit Pressure....................... 18

5. Sensitivity to Exit Mach Number........................ 20

6. Cu0 Cluster Distribution Parameters....................... 22 


\section{SUMARY}

Nucleation of copper vapor during gas expansion in a supersonic nozzle is investigated. Time scales for nucleation delay and supersaturation doubling are considered in establishing the need for non-steady state nucleation theory. A population balance model is constructed for tracking the size spectrum of stable clusters formed from self nucleation and exposed to supersaturated gas. It is found that at average cooling rates exceeding $10^{7} \mathrm{~K} / \mathrm{s}$, copper vapor exists in a highly nonequilibrium concentration at the nozzle exit. Copper condensation is severely limited by the nucleation kinetics and the available residence time. It is influenced by the monomer concentration and the nozzle exit pressure and temperature. The size spectrum of stable clusters is dominated by small clusters containing fewer than fifteen molecules. Nucleation persists throughout the expansion process because of the inability of the vapor condensation processes to relieve supersaturation buildup due to rapid gas cooling. Nucleation rate is sensitive to the surface energy of the clusters corresponding to the critical size. Monte-Carlo simulations of admissible cluster configurations are recommended for determining statistically-averaged surface energies of clusters containing two-totwenty molecules. 


\subsection{INTRODUCTION}

High-enthalpy arc heaters are being considered as a means of providing simulated test gas in ground test facilities for hypersonic propulsion systems. Erosion of copper electrodes in smaller arc heaters has been observed and is of concern. From the standpoint of characterizing the test environment, it is important to estimate the concentration of copper contaminant in the gas stream and to determine the behavior of copper vapor as the arc-heated gas is expanded in a supersonic nozile to simulated engine conditions. This report analyzes the condensation behavior of copper vapor during the expansion process.

A typical ground simulation of flight Mach number 15 involves heating air at $46 \mathrm{~atm}$ stagnation pressure to $2840 \mathrm{~K}$ and rapidly expanding the hot gas to Mach 3.5 in a supersonic nozzle. At nozzle exit, the static gas temperature is $1000 \mathrm{~K}$, and the static pressure is $0.5 \mathrm{~atm}$. From past experience with electrcde loss in a laboratory arc heater, the expected range of mole fraction of copper in the gas phase is $10-100 \mathrm{ppm}$. Corresponding to the higher estimate, the partial pressure of copper at nozzle exit is $5.1 \mathrm{~Pa}$. As a compari son, the saturation pressure of copper over the bulk at $1000 \mathrm{~K}$ is $2.5 \times 10^{-6}$ $\mathrm{Pa}$ and implies a supersaturation ratio of $2 \times 10^{6}$ for copper vapor. At this level of supersaturation, vapor species is susceptible to spontaneous nucleation. The purpose of this investigation is to follow the evolution of stable copper clusters formed from the homogeneous nucleation process.

Although steady-state nucleation theory is often used to describe cluster formation, its validity must be questioned in light of the rapid gas cooling rate in the nozzle. There are two relevant time scales: nucleation delay time and the supersaturation doubling time. The nucleation delay time refers to the incubation time to achieve steady-state cluster distribution at given supersaturation. It can be shown that

$$
\tau_{n}=\frac{1}{4}\left(\frac{2 \pi m}{k T}\right)^{1 / 2} \frac{4 \pi \sigma}{P_{v}(\ell n S)^{2}}
$$

where $S$ denotes the supersaturation, $P_{v}$ the partial pressure, 0 the surface energy, $T$ the gas temperature, $m$ the mass of a molecule, and $k$ the Baltzmann constant (Kanne-Dannetschek and Stauffer, 1981). The nucleation delay time alone is the appropriate time scale for an isothermal process. For a nonisothermal process, a second time scale for change in state points can be established by following the change in supersaturation ratio. From the definition of supersaturation, $S=P_{v} / P_{S}$ where $P_{S}$ is the saturation pressure, 


$$
\frac{1}{S} \frac{d S}{d T}=\frac{1}{P} \frac{d P}{d T}-\frac{1}{P} \frac{d P_{S}}{d T} .
$$

One can define the supersaturation dowbling time $\tau_{s}$ as the time required for a $100 \%$ change in supersaturation, i.e., $\Delta S / S=1$. Thus

$$
\tau_{S}=\frac{1}{\left(\frac{1}{P} \frac{d P}{d T}-\frac{l}{P_{S}} \frac{d P}{d T}\right) \frac{d T}{d t}}
$$

For the steady-state nucleation theory to be valid, $\tau_{n}$ must be much smaller than $\tau_{s}$. Figure 1 shows the relative magnitudes of $\tau_{s}$ and $\tau_{n}$ for an isentropic expansion in a nozzle from a reservoir with stagnation pressure of 46 atm and $2840 \mathrm{~K}$ stagnation temperature. The nucleation delay time is seen to be larger than the supersaturation doubling time for copper concentration less than $100 \mathrm{ppm}$ and gas cooling rate faster than $10^{6} \mathrm{~K} / \mathrm{s}$. As noted earlier, the expected range of copper concentration in the arc-heated gas stream is 10-100 ppm. A representative value for gas residence time in the supersonic nozzle flow is $0.1 \mathrm{~ms}$ which gives an average cooling rate of $2 \times 10^{7} \mathrm{~K} / \mathrm{s}$. Thus, we need to pursue a non-steady state formulation of nucleation theory.

A 'critical cooling rate' can be identified from Eqs. (1) and (2) at which $\tau_{s}=\tau_{n}$. Figure 2 displays the calculated critical cooling rate as a function of nozzle exit Mach number and copper concentration. The results reinforce the need for pursuing the non-steady state nucleation theory.

\subsection{THEORY}

Non-steady state nucleation has been formulated in literature using the liquid drop model, molecular dynamics simulation (Lippman, Schieve arid Canestaro, 1984) and chemical kinetics model (Bauer and Frurip, 1977). Of the three approaches, the liquid drop formulation is the simplest and is adopted in this work. It presumes that cluster growth is governed by a series of bimolecular addition reactions and neglects cluster-cluster and three-body reactions. The latter assumption is inapplicable for the initial dimerization and, perhaps, larger clusters such as trimers which must involve a third body. The chemical kinetics models do not invoke this restrictive assumption, but suffer from the difficulties associated with estimating rate constants for bimolecular and trimolecular reactions. The molecular dynamics simulations incur tedious statistical calculations that require knowledge of force constants which are usually not available. 


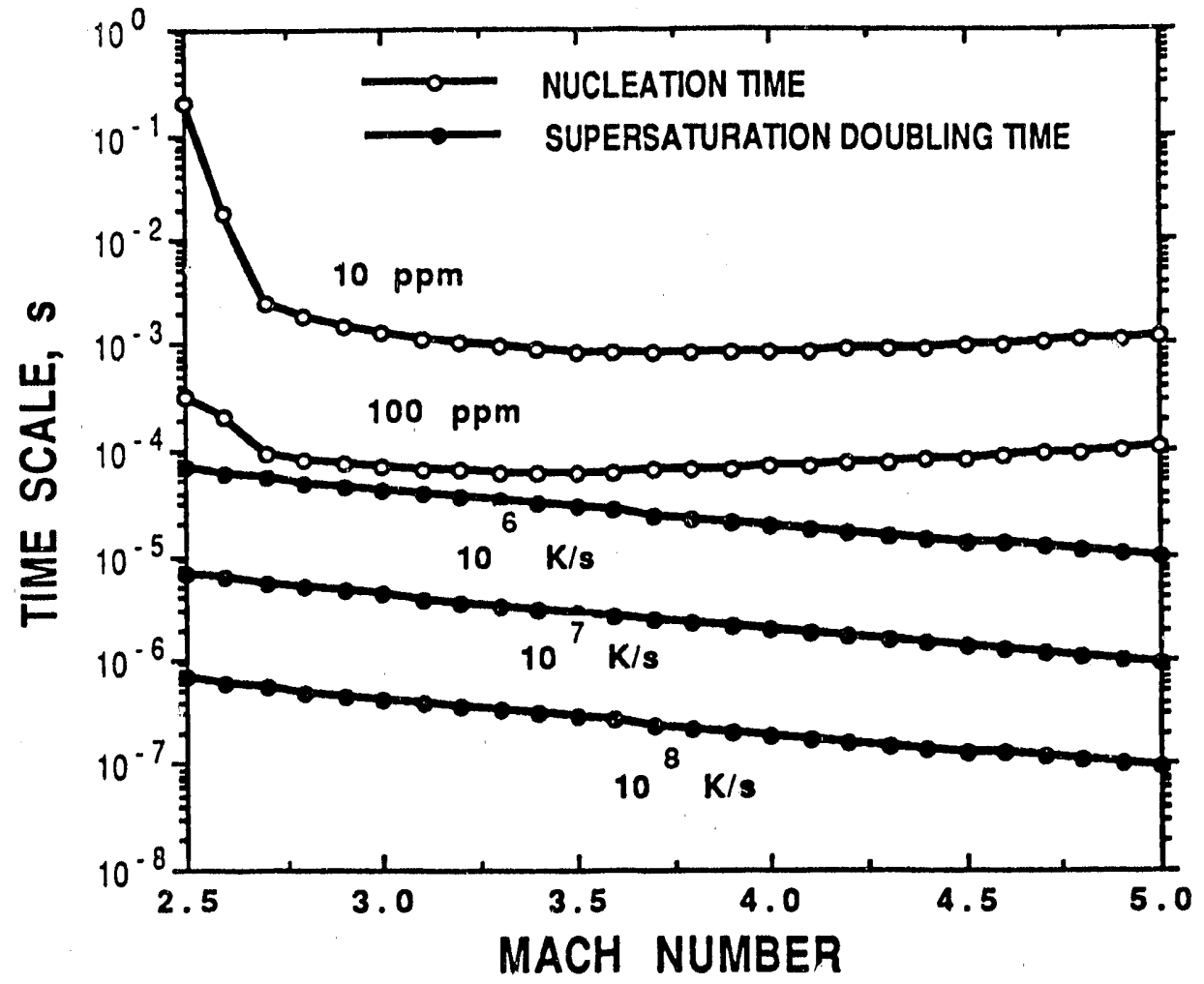

Fig. 1. Time Scales for Nucleation Delay and Supersaturation Doubling

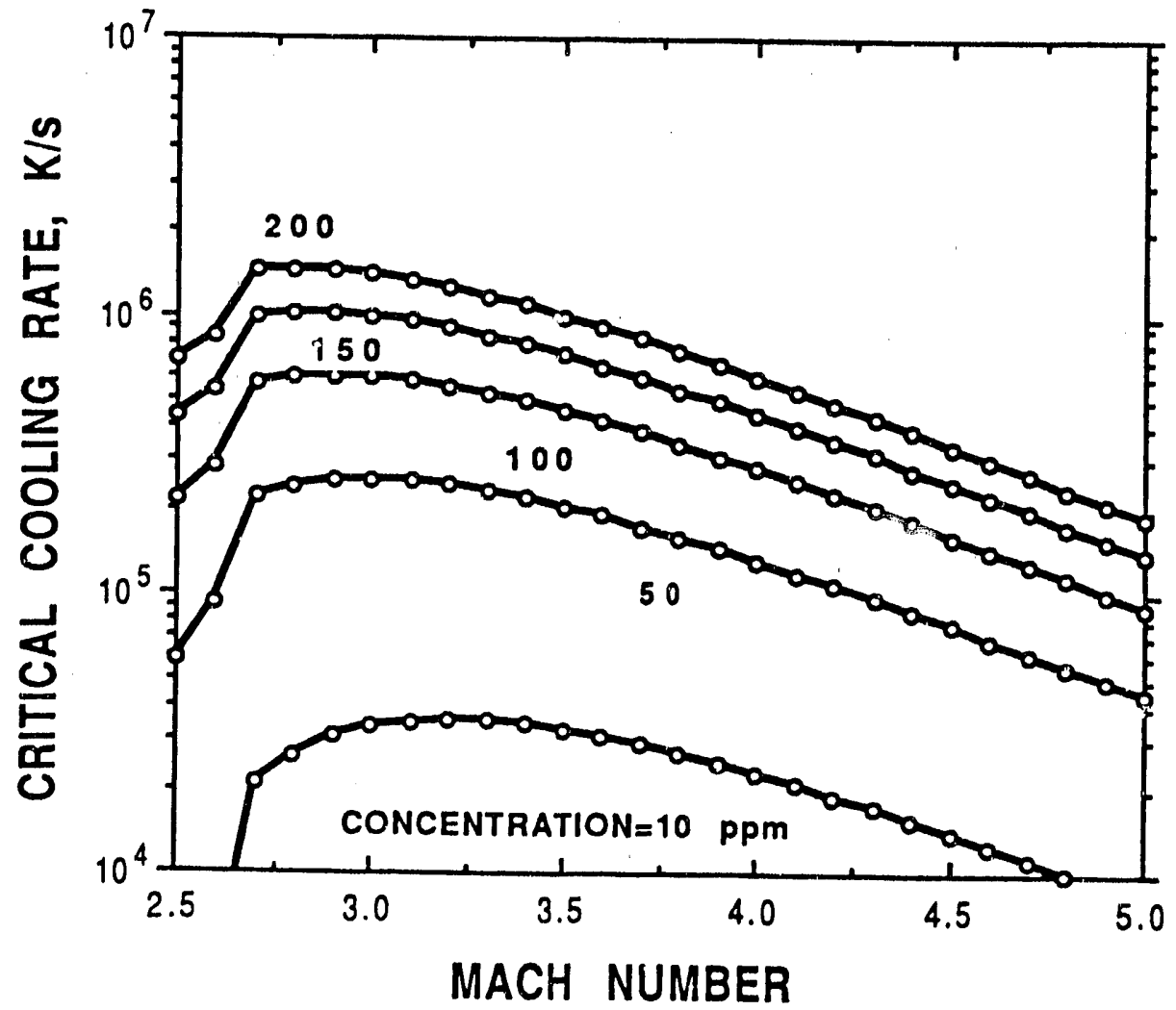

Fig. 2. Critical Cooling Rate 
The main interest in this study is not confined to nucleation kinetics, but extends to the disposition of stable clustirs formed from self nucleation. For this reason, a population balance model is constructed to track the evolution of the size spectrum of the stable clusters entrained and exposed to the supersaturated gas in the nozzle flow field.

\subsection{NON-STEADY STATE MUCLEATION THEORY}

The kinetics of cluster growth may be represented as a series of stepwise elementary reactions between the clusters and the monomers (Abraham, 1974).

$$
A_{i-1}+A_{1}-A_{i}
$$

The forward reaction denotes an accretion process involving combination between an (i-1)mer and a monomer $\left(A_{1}\right)$ to form an imer $\left(A_{j}\right)$. The reverse reaction denotes an evaporative loss of a monomer from an imer. The net flow between $A_{i-1}$ and $A_{i}$ is

$$
I_{i-1}=C_{i-1} A_{i-1}-E_{i} A_{i}
$$

where $C_{i-1}$ is the rate at which molecules (monomers) condense on the clusters $A_{j-1}$, and $E_{j}$ is the rate at which molecules evaporate from the cluster $A_{j}$. Following a similar argument, the net flow between the clusters $A_{j}$ and $A_{j+1}$ in the population is

$$
I_{i}=C_{i} A_{i}-E_{i+1} A_{i+1} \cdot
$$

In the foregoing kinetic scheme, a cluster $A_{j}$ may be formed by monomer accretion to $A_{i-1}$ or by evaiporation of a monomer from $A_{i+1}$. It decays by monomer accretion to $A_{j}$ or by monomer loss from $A_{j}$. Thus, the master equation for $A_{i}$ is

$$
\frac{d A_{i}}{d t}=I_{i}-I_{i-1}+\frac{A_{i}}{\rho} \frac{d p}{d t}
$$

An expression for the condensation rate can be developed by representing the cluster $A_{i}$ as a spherical aggregate of $i$ molecules with an equivalent radius of $r_{i}=i^{1 / 3} r_{0}$, where $r_{0}=\left(3 \mathrm{~m} / 4 \pi \rho_{c}\right)^{1 / 3}$, and $\rho_{c}$ is ine condensate density. The hard sphere cross-sectional area for collision between an imer and a monomer is $\pi\left(r_{i}+r_{0}\right)^{2}$. From the kinetic theory of gases, the average relative velocity between $A_{i}$ and $A_{1}$ is $\left(8 \mathrm{kT} / \pi \hat{m}_{j}\right)^{1 / 2}$ where $\hat{m}_{j}$, the reduced mass, is equal to $(i / 1+i) m$. Let $a_{j}$ represent the accommodation coefficient, 
that is, the fraction of molecules striking the cluster that stick. Then, it follows that

$$
C_{i}=\alpha_{i} \beta_{i} i^{2 / 3} A_{1}
$$

where

$$
\beta_{i}=\left(1+1 / i^{1 / 3}\right)^{2}(1+1 / i)^{1 / 2}(k T / 2 \pi m)^{1 / 2} 4 \pi\left(3 m / 4 \pi \rho_{c}\right)^{2 / 3} .
$$

An expression for the evaporation rate can be developed from the principle of microscopic reversibility. Accordingly,

$$
E_{i}=\left(A_{i-1}^{e} / A_{i}^{e}\right) C_{i-1}
$$

where the superscript e denotes the eqi:ilibrium value. The classical liquiddrop theory of thermodynamics of cluster formation relates the equilibrium concentration of the imers to the macroscopic volume and surface free energies. According to the classical thermodynamics,

$$
A_{i}^{e}=A_{1}^{e} \exp \left(i \operatorname{lnS}-\mu i^{2 / 3}\right)
$$

where $A_{1}^{e}$ is the concentration of monomers in equilibrium with bulk, $S$ is supersaturation $\left(A_{1} / A_{1}^{e}\right)$ and $\mu$ is related to the surface energy of the cluster (o) as

$$
\mu=4 \pi\left(\frac{3 m}{4 \pi \rho_{c}}\right)^{2 / 3} \frac{\sigma}{k T} .
$$

A critical size i* can be identified as the number of molecules in the cluster present in smallest concentration.

$$
i \star=(2 \mu / 3 \ell n S)^{3}
$$

Relative to the critical size, conventionally defined as the nucleus, $E_{i}$ displays the following functional behavior.

$$
\begin{aligned}
& E_{i}>C_{i} \text { for } i<i^{\star} \\
& E_{i}=C_{i} \text { for } i=i^{\star} \\
& E_{i}>C_{i} \text { for } i>i \star
\end{aligned}
$$


Many numerical solutions to the master equation, (Eq. 7), have been reported in literature for an isothermal gas $(d \rho / d t=0)$. These are generally based on the assumption that the steady-state concentration of small clusters (for example, 19-molecule clusters in Courtney, 1962) is established rapidiy and is equal to the equilibrium concentration. We need to relax these assumptions since our interest is in rapid gas expansion, cooling rate greater than $10^{5}$ $K / S$, leading to $S \gg 10^{3}$ and $i *$ as small as 2-3. Thus, we seek, a direct solution to Eq. (7) for all $i \geq 2$ by posing it as a set of stiff ordinary differential equations and solving by an implicit method in the GEAR package (Hindmarsh, 1972).

\subsection{STABLE CLUSTER POPULATION}

We determine the size distribution of the stable clusters $i \geq i$ from the population balance equation.

$$
\frac{\partial n}{\partial t}+\frac{\partial}{\partial r}(\dot{r} n)=J \delta\left(r \cdots r^{\star}\right)+\frac{n}{\rho} \frac{\partial \rho}{\partial t}+\left(\frac{\delta n}{\delta t}\right)_{c 011}
$$

In the foregoing, $n(r, t)$ is the distribution function, $r$ is the cluster size, $r^{\star}$ is the critical radius corresponding to a nucleus of $i *$ molecules, $J$ is the nucleation rate, and $(\delta \mathrm{n} / \delta \mathrm{t})$ coll refers to the rate of change of $n$ due to agglomeration of clusters. Consistent with the nicleation theory, the agglomeration term is dropped because the residence time of interest is of the order of milliseconds only. We identify the nucleation rate $J$ with the current $I_{i \star}$ determined from the solution of the master equation, Eq. (7).

From kinetic theory of gases, the following expression for growth rate $\dot{r}$ in the free-molecular limit can be derived upon accounting for the relative thermal motion between the monomers and the clusters, and the Kelvin effect.

$$
\dot{r}=\alpha_{i}\left(1+\frac{1}{i 1 / 3}\right)^{2}\left(1+\frac{1}{i}\right)^{1 / 2} \frac{P_{v}\left(1-s^{r^{*} / r-1}\right)}{\rho_{c}(2 \pi m k T)}
$$

where $P_{V}$ is the partial pressure of the monomers.

Equation (15) can be transformed into an ordinary differential equation by replacing the continuous function $n$ with a discrete number density function $N_{j} \cdot$

$$
N_{j}=\int_{r_{j}-\Delta r_{j / 2}}^{r+\Delta r} n d r
$$


where $\Delta r_{j}$ represents the bin size. Integrating Eq. (15) over discrete bins, we obtain

$$
\frac{d N_{j}}{d t}=-F_{j+1}+F_{j}+J_{j}+\frac{N_{j}}{\rho} \frac{d \rho}{d t}
$$

where

$$
F_{j}=\dot{r}_{j-1 / 2}\left|\frac{N_{j-1}}{\Delta r_{j-1}}, \frac{N_{j}}{\Delta r_{j}}\right|
$$

An upwinding convention applies to Eq. (19): the first term inside the bracket is used if the multiplier is positive and the second if the multiplier is negative. Equation (18) represents a set of cuupled ordinary differential equations and can be solved by the same technique as for the master equation, Eq. (7).

\subsection{MONOMER CONCENTRATION}

The depletion in monomer concentration due to the formation of stable clusters and condensation on the stable clusters is governed by the following conservation equation.

$$
\frac{d A_{1}}{d t}=\frac{A_{1}}{\rho} \frac{d \rho}{d t}+\sum_{j} \frac{4}{3} \pi r_{j}^{3} \frac{\rho_{c}}{m}\left[\frac{N_{j}}{\rho} \frac{d \rho}{d t}-\frac{d N}{d t}\right]
$$

Equations (7), (18) and (20) represent a set of coupled, stiff ordinary differential equations and were solved numerically by the GEAR's backwarddifferencing implicit scheme.

\subsection{RESULTS AND DISCUSSION}

The foregoing cluster evolution model has been applied to isentropic gas expansion $(\gamma=1.3)$ in the diverging portion of a supersonic nozzle with $8.5^{\circ}$ half angle and $3.81 \mathrm{~cm}$ throat diameter. The reservoir conditions and the nozzle length are determined from the specified exit Mach number, gas pressure and gas temperature. 
The vapor pressure of copper (and copper oxide) is calculated from the JANAF thermodynamic data for ideal gas and condensed states (Chase et al., 1985). Table 1 lists the reference values of surface energy, copper concentration and nozzle exit conditions around which sensitivity calculations have been performed.

Table 1. Reference Data

\begin{tabular}{cccccccc}
\hline & 0 & $P_{e}$ & $T_{e}$ & $M_{e}$ & Mole Fraction & $\rho_{\mathrm{C}}$ \\
\hline Cu & $0.8 \mathrm{~N} / \mathrm{m}$ & $0.5 \mathrm{~atm}$ & $1000 \mathrm{~K}$ & 3.5 & $100 \mathrm{ppm}$ & $8,920 \mathrm{~kg} / \mathrm{m}^{3}$ \\
CuO & $0.6 \mathrm{~N} / \mathrm{m}$ & $0.5 \mathrm{~atm}$ & $1000 \mathrm{~K}$ & 3.5 & $100 \mathrm{ppm}$ & $6,400 \mathrm{~kg} / \mathrm{m}^{3}$ \\
\hline
\end{tabular}

\subsection{CLUSTER DYNAMICS}

For purpose of illustration, one calculation was performed for an isothermal gas at $1200 \mathrm{~K}$ and $1 \mathrm{~atm}$. The concentration of copper is taken as $2 \mathrm{ppm}$ which corresponds to a supersaturation of 138. For the master equation, the imposed initial condition is $A_{j}=0$ for all $i>1$. In this exercise, the population balance equation is disregarded.

Figure 3 depicts the transient variation in cluster concentration and its approach to the steady-state distribution in $10 \mathrm{~ms}$. At steady state,

$$
I_{i}=I_{i+1} \text { for } 811 i
$$

and the cluster current is constant and independent of cluster size. Also included is the equilibrium distribution of the clusters, defined as

$$
I_{i}=0 \text { for a } 171 \text {. }
$$

The equilibrium distribution has a marked minimum at $i=i^{\star}$. For $i<i^{\star}$, the steady-state distribution is coincident with the equilibrium distribution. Note also the rapid approach of dimer to the equilibrium value which constitutes the basis of equilibrium assumption for small clusters in many nonsteady nucleation analyses.

\subsection{SENSITIVITY TO SURFACE ENERGY}

The liquid drop model assumes a constant value of specific surface energy regardless of the cluster size. This value is customarily equated to the bulk 


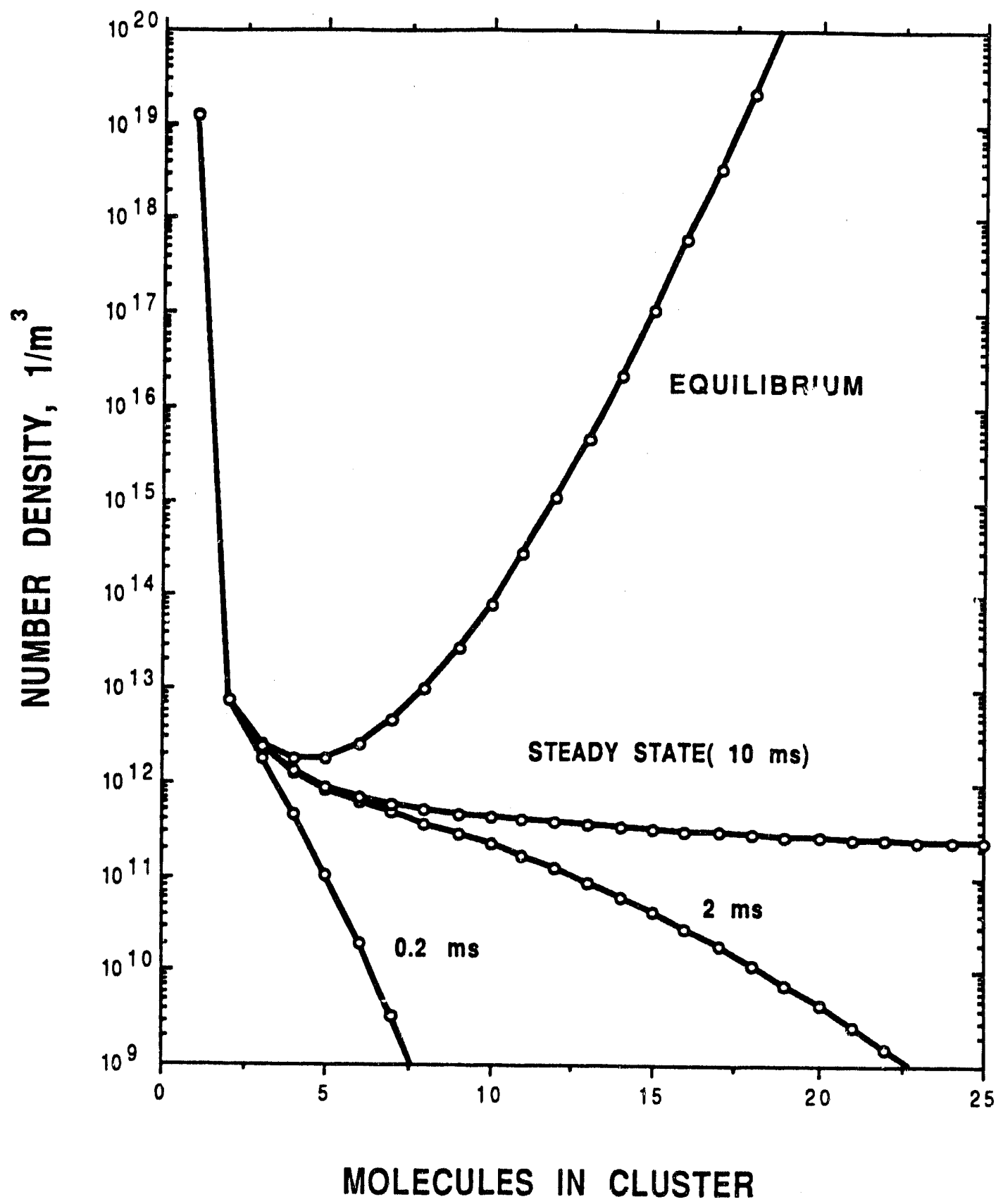

Fig. 3. Cluster Dynamics 
surface tension. Monte Carlo simulations of cluster configurations, however, reveal surface energy to be a fraction of the cluster size particularly for sma11 clusters containing fewer than 10-20 molecules. For simple molecules like $\mathrm{Ar}$, the statistically averaged surface energy of ten-atom clusters has been calculated to be about $20 \%$ less than that of the bulk. The surface tension of metals is temperature dependent and generally lies in the range 1-1.4 $\mathrm{N} / \mathrm{m}$. Copper has a surface tension of $1.2 \mathrm{~N} / \mathrm{m}$ at its melting point. Since we are potentially interested in clusters as small as dimers and trimers, we choose a smailer value $(0.8 \mathrm{~N} / \mathrm{m})$ as the reference and conduct a sensitivity study on cluster distribution as a function of $a$.

Figure 4 depicts the calculated number density distribution of stable clusters at nozzle exit as a function of $o$. These calculations are based on the gas dynamic conditions determined from Table 1 reference data. The flow residence time $\left(\tau_{r}\right)$ in the diverging section is $0.138 \mathrm{~ms}$. The condensation time, defined as the residence time in which $S$ is greater than 1 , is 0.094 ms. It was found sufficient to consider up to 30 -atom clusters in the nonsteady nucleation model. The population balance equation was solved using twenty unequal size bins.

The calculated stable cluster size distribution is dominated by the small clusters, i.e., dimers and trimers. The number density decreases with cluster size and surface energy. The slight upturn in the last size bin should be regarded as a numerical aberration attributed to the finite limit in the maximum cluster size considered. The extent of condensation is limited by the available residence time in the nozzle and is a strong function of surface energy. For the three vaiues of o considered, the calculated amount of copper condensed was $0.10 \%$ for $\sigma=1 \mathrm{~N} / \mathrm{m}, 0.30 \%$ for $\sigma=0.8 \mathrm{~N} / \mathrm{m}$ and $29.81 \%$ for $\sigma=$ $0.6 \mathrm{~N} / \mathrm{m}$. In each case, the rise in supersaturation because of the drop in temperature from gas expansion is not compensated by the ensuing homogeneous nucleation and condensation. There is a resultant monotonic increase in supersaturation along the flow direction. At nozzle exit, magnitude of $S$ exceeding $10^{6}$ has been calculated.

Figure 5 depicts the rise in supersaturation ratio with gas expansion. As $S$ increases, the critical cluster size $j *$ decreases in accordance with Eq. (13), and the nucleation process accelerates. At $S=\exp \left(2^{2 / 3} \mu / 3\right)$, the critical cluster size reduces to a dimer. Above this value of supersaturation, i* becomes independent of $S$, and the nucleation rate levels off. At this point, $J$ becomes a function of monomer concentration only and is independent of the supersaturation level.

With reference to Eqs. (15) and (20), vapor depletion occurs by two 


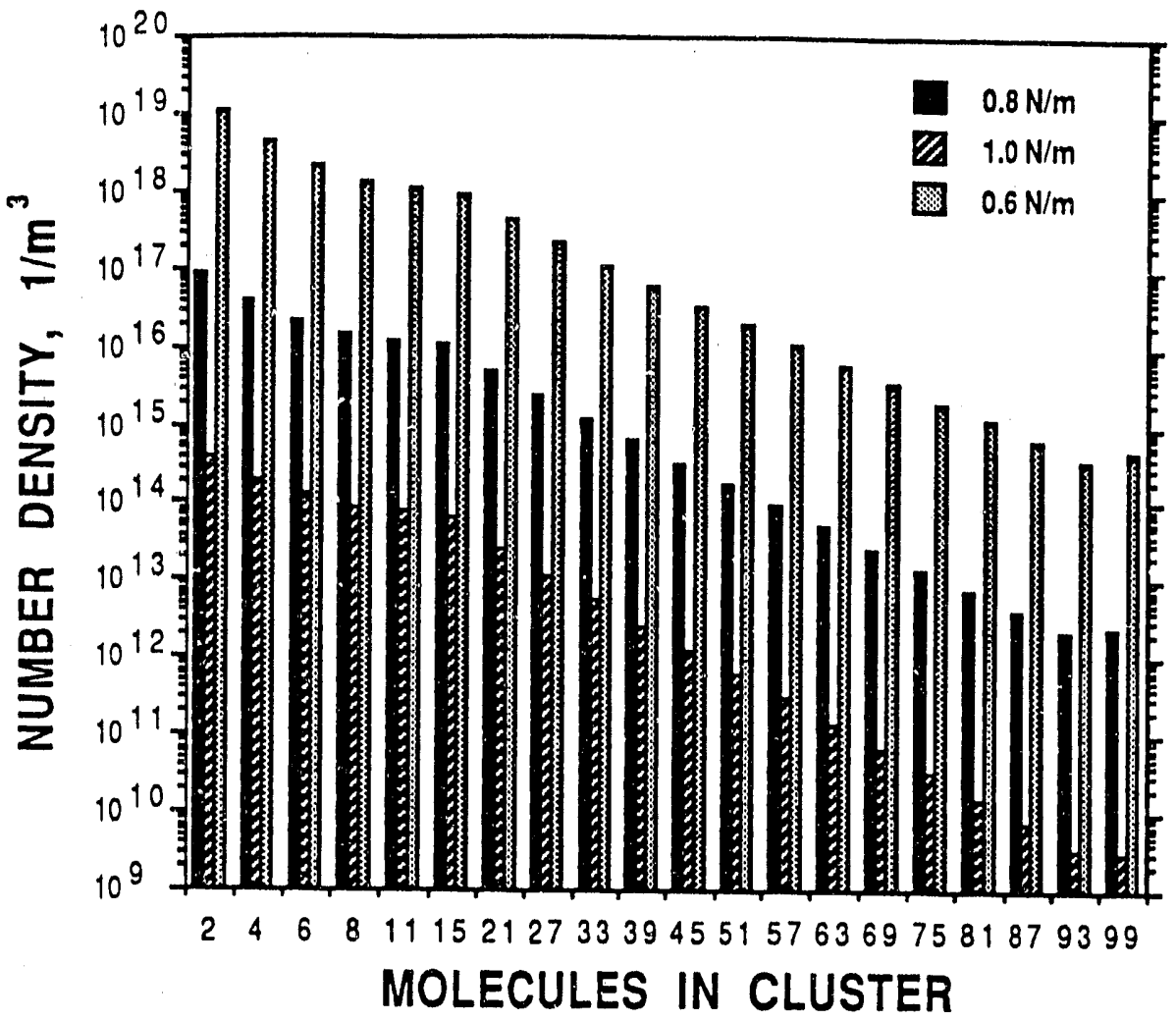

Fig. 4. Sensitivity of Stable Cluster Size Spe:trum to Surface Energy $\left(T_{e}=1000 \mathrm{~K}, P_{e}=0.5 \mathrm{~atm}, M_{e}=3.5, X_{i}=100 \mathrm{ppm}\right)$

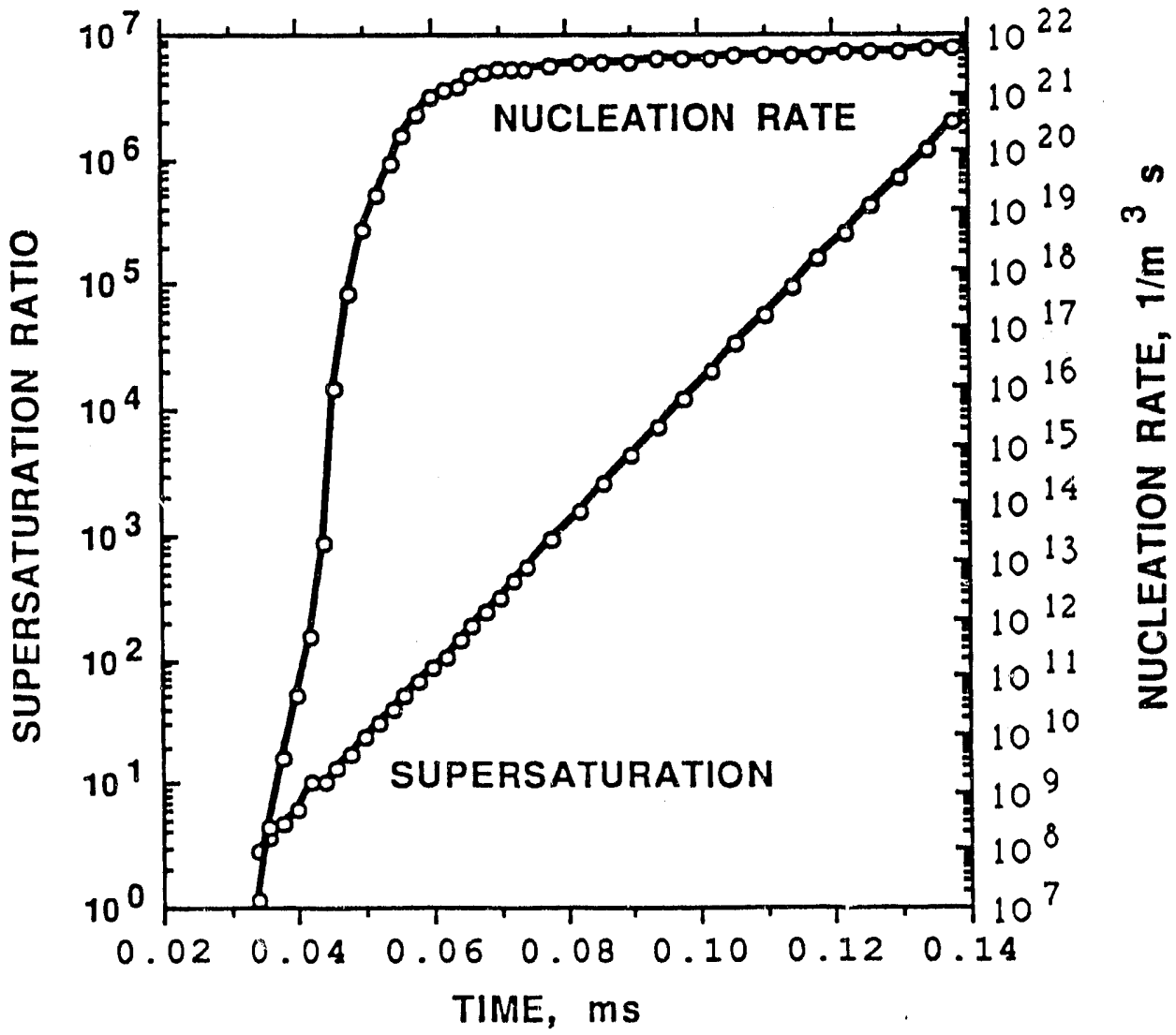

Fig. 5. Variation of Supersaturation Ratio and Nucleation Rate During the Expansion Process $\left(T_{e}=1000 \mathrm{~K}, P_{e}=0.5 \mathrm{~atm}, M_{e}=3.5\right.$, $x_{i}=100 \mathrm{ppm}, \sigma=0.8 \mathrm{~N} / \mathrm{m}$ ) 
processes: homogeneous nucleation to form embryos/nuclei and vapor condensation on the embryos. In clean gases, the homogeneous nucleation process forms embryos and provides sites for vapor condensation. In general, even though homogeneous nucleation is the initiator, much of the mass transfer occurs through vapor condensation on the embryos. The relative amounts of condensation by the two processes can be calculated from the following equations.

$$
\begin{aligned}
& \Delta \rho_{v} \text { (nucleation) }=\int \frac{4}{3} \pi r^{\star}{ }^{3} \rho_{c} \mathrm{~J} d t \\
& \Delta \rho_{v} \text { (condensation) }=\iint 4 \pi r^{2} \dot{r}_{\rho_{c}} n d r d t
\end{aligned}
$$

As mentioned above, during the supersonic expansion $S$ was calculated to increase along the flow direction. In the short residence time expansion process, J was persistently large so that nucleation dominated over the condensation process. This is also evident in the declining number density witi cluster size seen in Fig. 4.

\subsection{SENSITIVITY TO MONOMER CONCENTRATION}

Figure 6 depicts the dependence of cluster size distribution at nozzle exit on initial copper vapor concentration. At low mole fraction, the number density decreases rapidly with cluster size. At 100 ppm, larger clusters begin to appear in the size distribution. When the initial concentration is increased to $200 \mathrm{ppm}$, the cluster distribution tends to become uniform with a small internal peak at 15-molecule size. As mentioned earlier, cluster segregation in the last size bin is an artifact of the numerical scheme and would disappear if larger clusters were included in the simulation.

Table 2 quantifies the cluster distribution in terms of the fraction of vapor condensed in the nozzle, and relative number density $\left(A_{99} / A_{2}\right)$, concentration $\left(\rho_{g g} / \rho_{2}\right)$ and surface area $\left(S_{9 g} / S_{2}\right)$ of 99 -molecule clusters to dimers.

Table 2. Sensitivity to Monomer Concentration

\begin{tabular}{ccccc}
\hline$X_{1}, \mathrm{ppm}$ & \% Condensed & $\mathrm{A}_{99} / \mathrm{A}_{2}$ & $\rho_{99} / \rho_{2}$ & $S_{99} / \mathrm{S}_{2}$ \\
\hline 50 & 0.08 & $<10^{-6}$ & $<10^{-6}$ & $<10^{-6}$ \\
100 & 0.30 & $2.75 \times 10^{-5}$ & $1.36 \times 10^{-3}$ & $3.7 \times 10^{-4}$ \\
200 & 2.85 & 0.031 & 1.54 & 0.420 \\
\hline
\end{tabular}




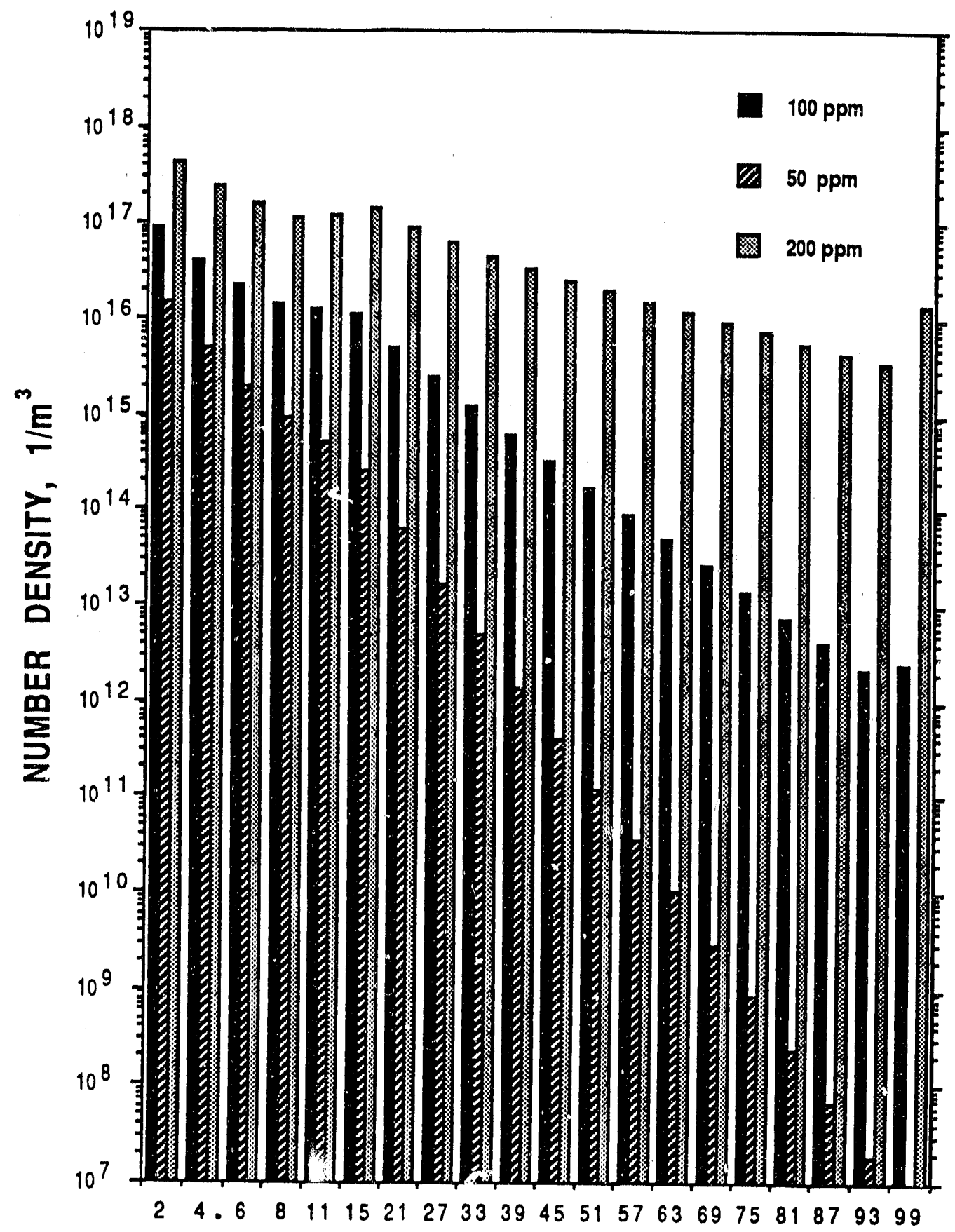

MOLECULES IN CLUSTER

Fig. 6. Effect of Monomer Concentration on Formation of Stable Clusters $\left(T_{e}=1000 \mathrm{~K}, P_{e}=0.5 \mathrm{~atm}, M_{e}=3.5, \sigma=0.3 \mathrm{~N} / \mathrm{m}\right)$ 


\subsection{SENSITIVITY TO EXIT TEMPERATURE}

Figure 7 displays the effect of nozzle exit temperature on the size distribution of the stable clusters. The nozzle exit pressure and Mach number are held constant in this set of calculations. The change in nozzle exit temperature is accomplished by varying the reservoir temperature. As the exit temperature is raised, lower levels of supersaturation are attained, and the flow residence time $\left(\tau_{c}\right)$ in which $S>1$ decreases. Thus, the amount of condensation is strongly dependent on the nozzle exit temperature. The cluster distribution parameters as a function of $T_{e}$ are sumarized in Table 3.

Table 3. Sensitivity to Nozzle Exit Temperature

\begin{tabular}{ccccccc}
\hline$T_{e}, K$ & $\tau_{r}, m s$ & $\tau_{c}, m s$ & \% Condensed & \multicolumn{1}{c}{$A_{9 g} / A_{2}$} & ${ }_{\rho_{9 g} / \rho_{2}}$ & $S_{9 g} / S_{2}$ \\
\hline 800 & 0.155 & 0.142 & 16.30 & 0.022 & 1.10 & 0.30 \\
1000 & 0.138 & 0.094 & 0.30 & $2.75 \times 10^{-5}$ & $1.36 \times 10^{-3}$ & $3.71 \times 10^{-4}$ \\
1200 & 0.127 & 0.052 & 0.08 & $<10^{-6}$ & $<10^{-6}$ & $<10^{-6}$ \\
\hline
\end{tabular}

\subsection{SENSITIVITY TO EXIT PRESSURE}

Figure 8 compares the stable cluster size distribution at two nozzle exit pressures, 0.5 and $1 \mathrm{~atm}$. The exit pressure is assumed to be controlled by the reservoir pressure. All other conditions are held constant, i.e., $\mathrm{T}_{e}=$ $1000 \mathrm{~K}, M_{e}=3.5, X_{1}=100 \mathrm{ppm}$ and $\sigma=0.8 \mathrm{~N} / \mathrm{m}$. Under this set of conditions, $S$ varies directly as $\mathrm{P}_{\mathrm{e}}$. The resuiting increase in the concentration of the large clusters is shown graphically in Fig. 8 and summarized in Table 4.

Table 4. Sensitivity to Nozzle Exit Pressure

\begin{tabular}{lccccc}
\hline$P_{e}$, atm & ${ }^{\tau_{c}}$, $m s$ & \% Condensed & $\mathrm{A}_{99} / \mathrm{A}_{2}$ & ${ }^{\rho_{9 g} / \rho_{2}}$ & $\mathrm{~S}_{99} / \mathrm{S}_{2}$ \\
\hline 0.5 & 0.094 & 0.30 & $2.75 \times 10^{-5}$ & $1.36 \times 10^{-3}$ & $3.71 \times 10^{-4}$ \\
1.0 & 0.100 & 2.93 & 0.031 & 1.55 & 0.421 \\
\hline
\end{tabular}




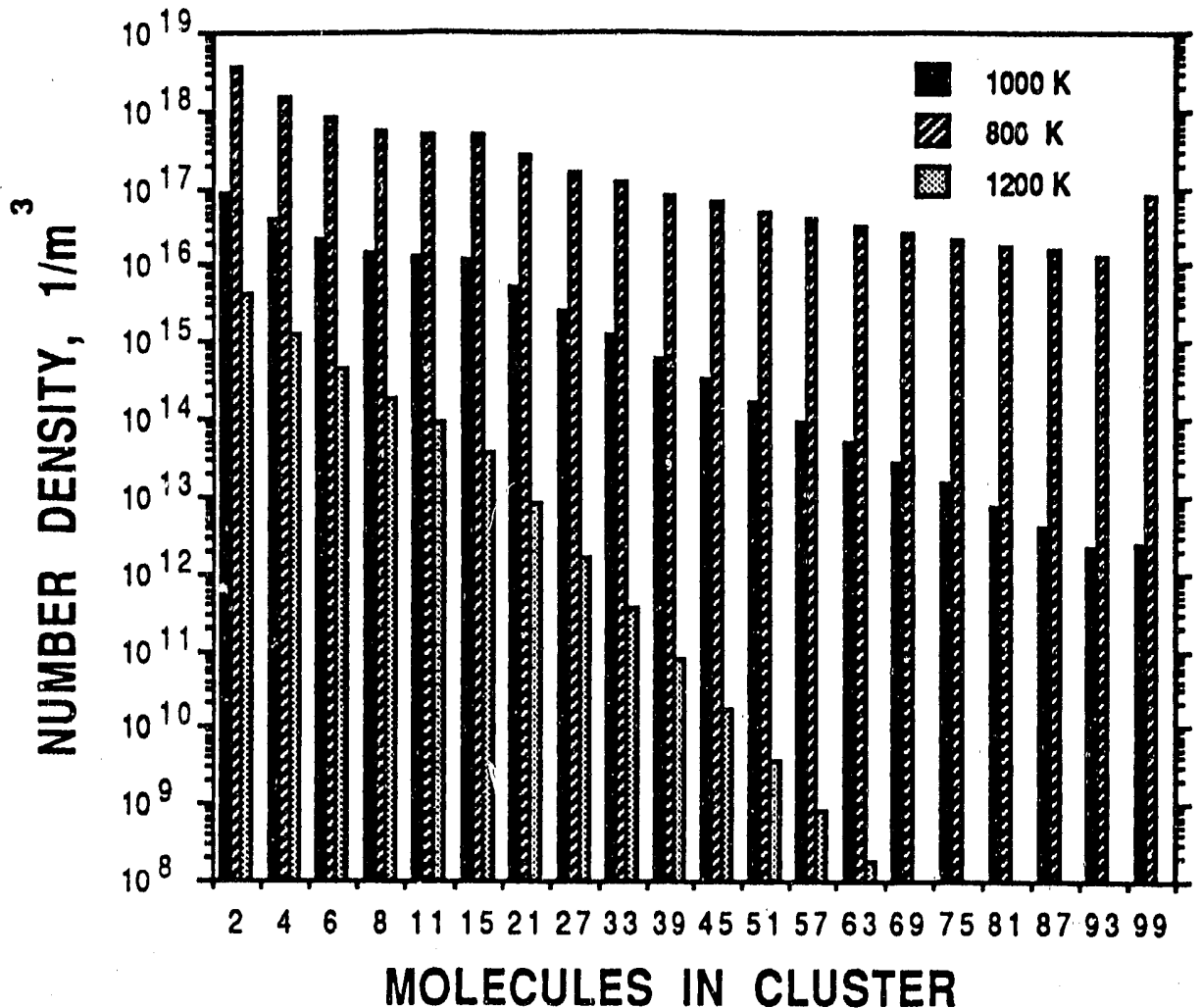

Fig. 7. Effect of Nozzle Exit Temperature on Formation of Stable Clusters $\left(P_{e}=0.5 \mathrm{~atm}, M_{e}=3.5, X_{i}=100 \mathrm{ppm}, \sigma=0.8 \mathrm{~N} / \mathrm{m}\right)$

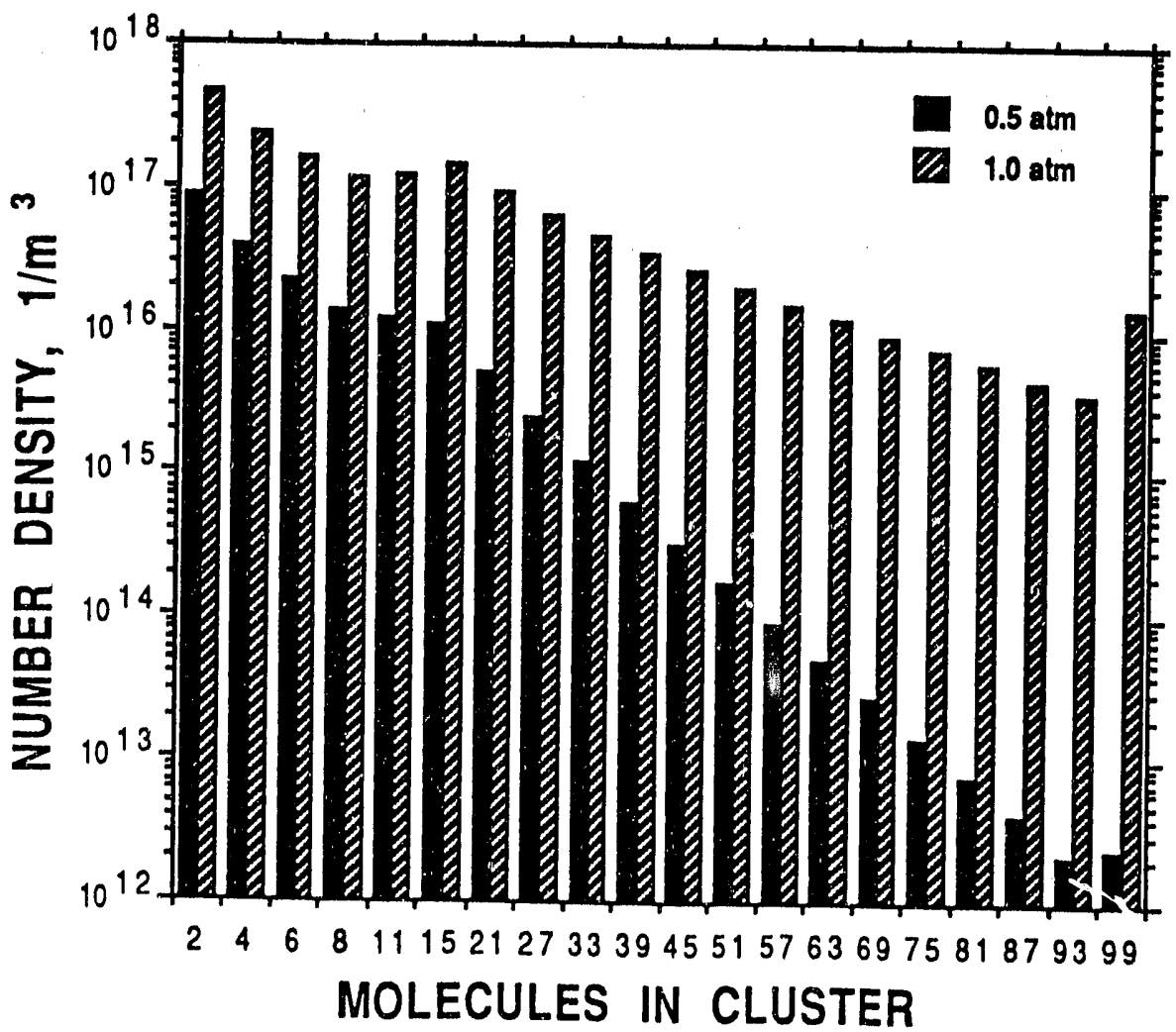

Fig. 8. Effect of Nozzle Exit Pressure on Formation of Stable Clusters $\left(T_{e}=1000 \mathrm{~K}, M_{e}=3.5, x_{j}=100 \mathrm{ppm}, \sigma=0.8 \mathrm{~N} / \mathrm{m}\right)$ 


\subsection{SENSITIVITY TO EXIT MACH NUMBER}

A set of calculations was done in which the nozzle exit Mach number was varied by changing the reservoir conditions but holding the exit pressure at $0.5 \mathrm{~atm}$ and temperature at $1000 \mathrm{~K}$. As depicted in Fig. 9, the calculated size distribution of stable clusters is only mildly sensitive to the nozzle exit Mach number varied in this manner. Table 5 shows the fractional increase in copper vapor condensed as the Mach number is changed from 3 to 4 .

Table 5. Sensitivity to Exit Mach Number

\begin{tabular}{lll}
\hline$M_{\mathrm{e}}$ & $\tau_{r}, \mathrm{~ms}$ & \% Condensed \\
\hline 3.0 & 0.103 & 0.27 \\
3.5 & 0.138 & 0.30 \\
4.0 & 0.178 & 0.47 \\
\hline
\end{tabular}

\subsection{COPPER OXIDE CONDENSATION}

Equilibrium thermodynamic calculations suggest that copper which exists as metaliic vapor in the arc heater can combine with oxygen to form cuo during nozzle expansion. A chemical kinetic barrier, however, may prevent oxidation of copper in a time scale of $0.1 \mathrm{~ms}$. The pertinent chemical rate constants are not available to permit a definitive assessment of the oxidation possibility. In order to assess the effect of oxide formation on copper nucleation, we disregard the possible chemical kinetic barrier. With this assumption, JANAF Gibbs free energy data alone can be employed to determine the saturation pressure of copper oxide.

The surface tension of metal oxides is generally lower than that of the metals and lies in the range $0.3-0.8 \mathrm{~N} / \mathrm{m}$. Within this range of $\sigma$, Figure 10 displays the calculated size distribution of stable CuO clusters at the nozzle exit. The results generally show the same trend as observed previously in Fig. 4 for copper clusters. Table 6 lists the distribution parameters. A noteworthy feature is that almost complete condensation of CuO is calculated for $\sigma=0.4 \mathrm{~N} / \mathrm{m}$. The distribution is heavily populated by clusters smaller than fifteen-molecule aggregates. On a concentration basis $\left(\rho_{i}=i A_{j}\right)$, $\rho_{j}$ is almost a constant for $i<20$. 


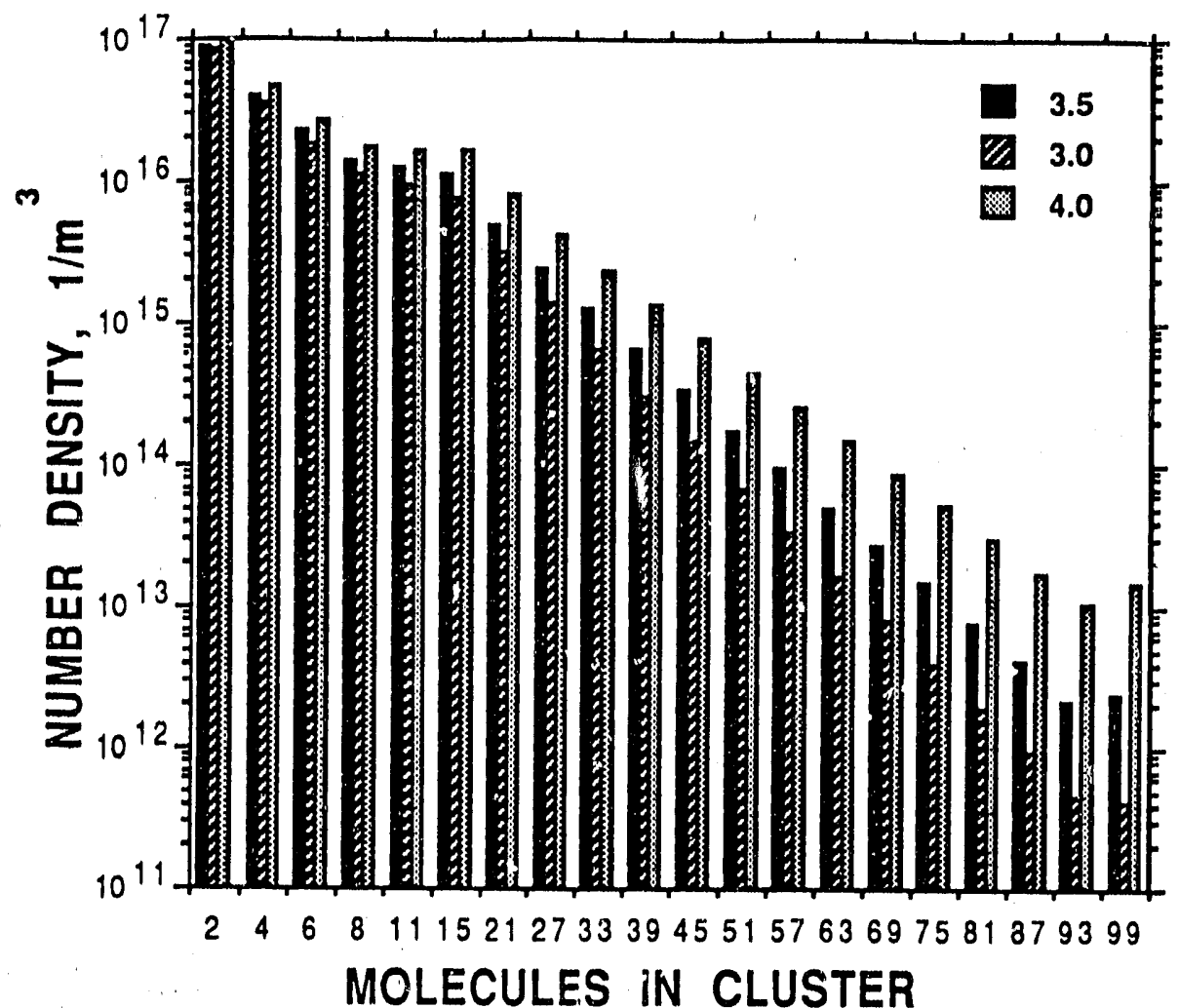

Fig. 9. Effect of Nozzle Exit Mach Number on Formation of Stable Clusters $\left(T_{e}=1000 \mathrm{~K}, P_{e}=0.5 \mathrm{~atm}, X_{i}=100 \mathrm{ppm}, \sigma=0.8 \mathrm{~N} / \mathrm{m}\right.$

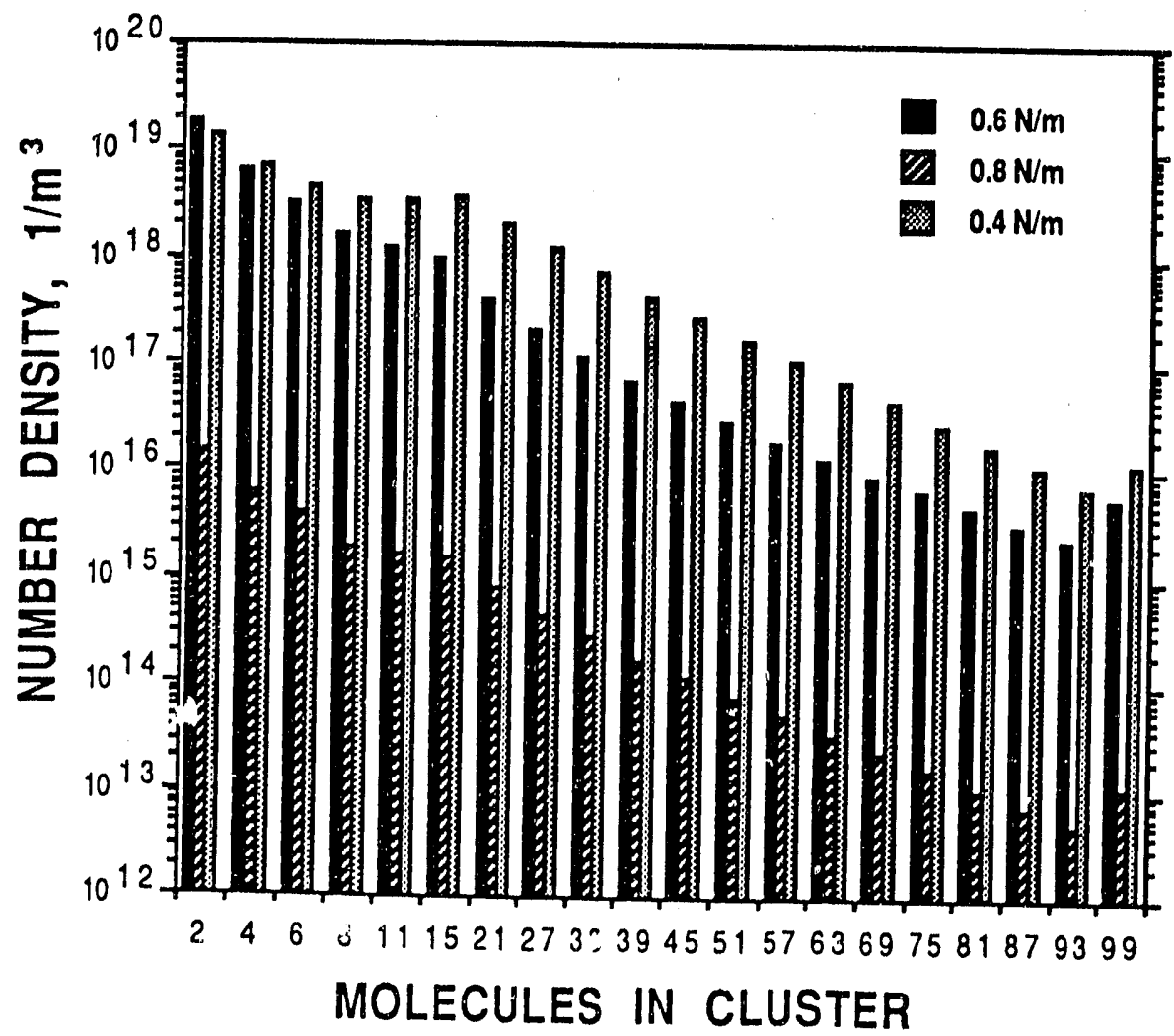

Fig. 10. Cu0 Condensation ( $T_{e}=1000 \mathrm{~K}, \mathrm{P}_{\mathrm{e}}=0.5 \mathrm{~atm}, \mathrm{M}_{\mathrm{e}}=3.5$, 
Table 6. Cu0 Cluster Distribution Parameters

\begin{tabular}{lcccc}
\hline $0 . \mathrm{N} / \mathrm{m}$ & $\%$ condensed & $\mathrm{A}_{99} / \mathrm{A}_{2}$ & $\rho_{99} / \rho_{2}$ & $\mathrm{~S}_{99} / \mathrm{S}_{2}$ \\
\hline 0.4 & 97.36 & $8.95 \times 10^{-4}$ & 0.044 & 0.012 \\
0.6 & 39.45 & $3.27 \times 10^{-4}$ & 0.016 & $4.41 \times 10^{-3}$ \\
0.8 & $<10^{-3}$ & $7.13 \times 10^{-4}$ & 0.035 & $9.61 \times 10^{-3}$ \\
\hline
\end{tabular}

\subsection{CONCLUSIONS AND RECOMMENDATIONS}

A non-steady nucleation theory based on the liquid drop model has been used to investigate the condensation behavior of copper vapor during supersonic expansion in a nozzle. The expansion process is characterized ty a residence time of the order of $0.1 \mathrm{~ms}$ from nozzle throat to exit and by an average gas cooling rate exceeding $10^{7} \mathrm{~K} / \mathrm{s}$. Little attention is paid to the subsonic flow in the converging section where the gas is highly superheated. The principal conclusions from this investigation are summarized below.

a) At the nozzle exit, copper vapor exists in a highly nonequilibrium state, $S \gg 10^{6}$. This is an outcome of the inability of homogeneous nucleation and vapor condensation processes to relieve supersaturation buildup due to rapid gas cooling. Consequently is increases monotonically along the flow direction.

b) Since high levels of $S$ are attained and maintained, the nucleation process persists at an ever-increasing rate. Much of the mass transfer is associated with the formation of the embryos with a small contribution from vapor condensation on the sites provided by the embryos. Thus, the size spectrum of the stable clusters is dominated by small clusters containing fewer than fifteen molecules.

c) Because of the short residence time in the nozzle, the amount of vapor condensation is limited by nucleation kinetics and can be much smaller than that determined from thermodynamic equilibrium. The extent of condensation is found to be sensitive to the copper vapor concentration at the inlet, and the nozzle exit pressure and temperature. Nucleation is expected to continue into the engine test section downstream of the nozzle. The calculation of stable cluster size evolution needs to be extended up to and perhaps beyond the ignition point in the combustor section. 
d) One source of uncertainty in the nucleation theory is the cluster surface energy. It is known to be smaller than the bulk liquid surface tension arí to depend upon the cluster size. We recommend Monte-Carlo simulations of cluster configurations from which statistically-averaged surface energy can be deduced.

e) For small clusters, the condensate density can be much smaller than the bulk material density. This is particularly true for clusters containing 2-15 atoms which dominate the calculated size spectra. We recommend MonteCarlo simulation of cluster configuration statistics to determine the size dependence of cluster density. We note from Eqs. (12) and (13) that the embryo size $i$ is directly proportional to $\sigma^{3} / \rho_{c}^{2}$. At steady state the nucleation rate is exponentially dependent on $i^{\star}$. Thus nucleation kinetics is extremely sensitive to $\sigma$ and $\rho_{c}$.

f) Finally, the calculated critical size of the embryos is smaller than the range in which the liquid drop model is normally used. Therefore, experimental data are needed to validate the nucleation theory applied to a rapid expansion process with cooling rate exceeding $10^{7} \mathrm{k} / \mathrm{s}$. 


\subsection{REFERENCES}

1. Abraham, F. F., 1974, Homogeneous Nucleation, Academic Press, NY.

2. Bauer, S. H. and Frurip, D. J., 1977, "Homogeneous Nucleation in Metal Vapors. 5. A Self-Consistent Kinetic Mode1," J. Phys. Chem., V i, 1 , No. 10, 1015-1024.

3. Chase et a1., 1985, JANAF Thermochemical Tables, J. Phys. Chem. Ref. Jata, Vo 1. 14, Supp1. 1.

4. Courtney, W. G., 1962, "Non-Steady-State Nucleation," J. Chem. Phys., Vol. 36. No. 8, 2009-2017.

5. Hindmarsh, A. C., 1972, "GEAR: Ordinary Differential Equation System Solver," Lawrence Livermore Laboratory, UDID-30001 Rev. 1.

6. Kanne-Dannetschek, I. and Stauffer, D., 1981, "Quantitative Theory for Time Lag in Nucleation," J. Aerosol Sci., Vo1. 12, No. 2, 105-108.

7. Lippman, D., Schieve, W. C., and Canestaro, C., 1984, "Clustering Time Dependence in Molecular Dynamics: A Kinetic Model," J. Chem. Phys., Vol. 81, No. 11, 4969-4974. 

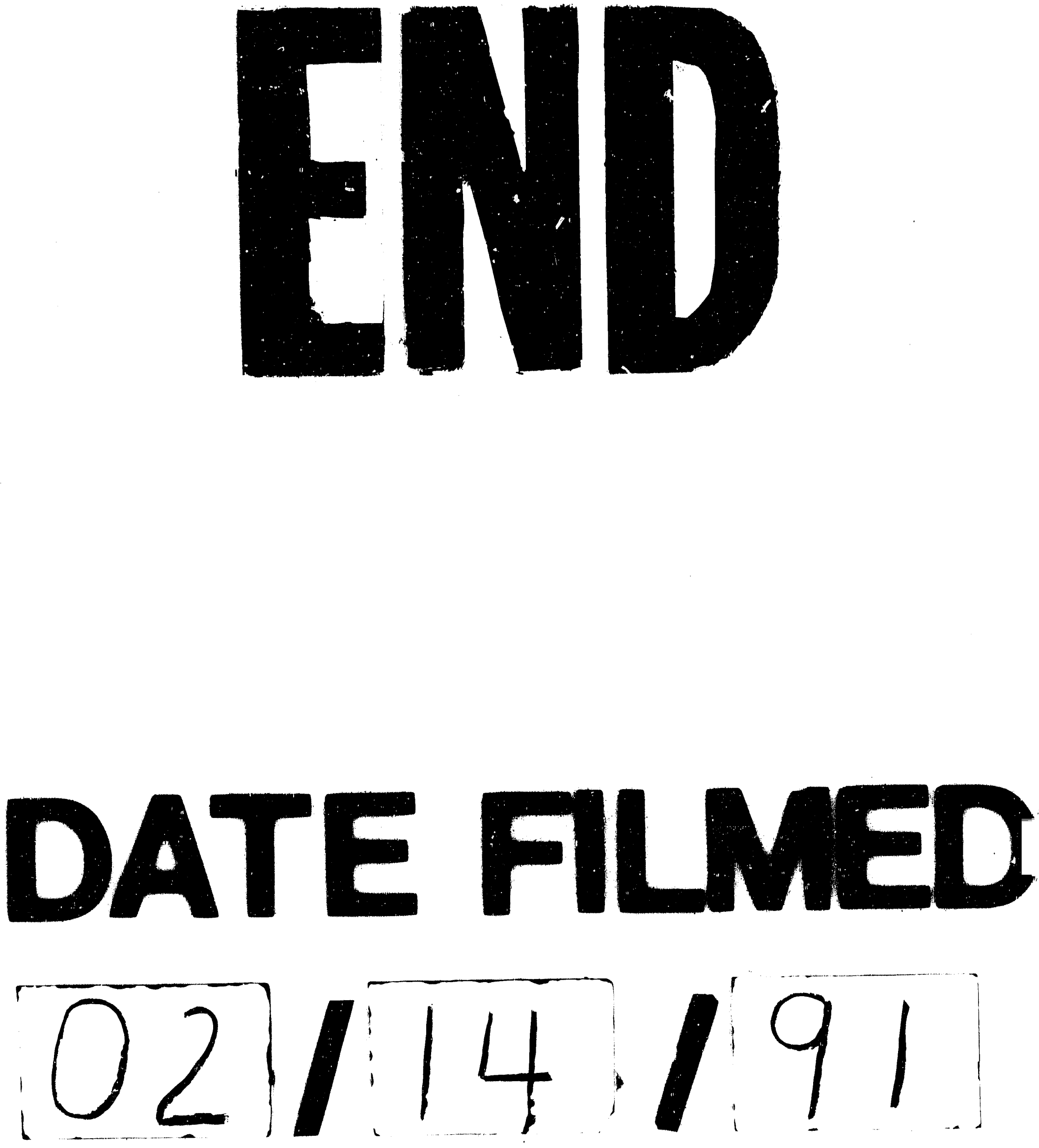
